\title{
The spatial scale of density-dependent growth and implications for dispersal from nests in juvenile Atlantic salmon
}

\author{
Sigurd Einum • Grethe Robertsen • Keith H. Nislow • \\ Simon McKelvey $\cdot$ John D. Armstrong
}

Received: 18 January 2010/Accepted: 17 September 2010/Published online: 6 October 2010

(c) The Author(s) 2010. This article is published with open access at Springerlink.com

\begin{abstract}
By dispersing from localized aggregations of recruits, individuals may obtain energetic benefits due to reduced experienced density. However, this will depend on the spatial scale over which individuals compete. Here, we quantify this scale for juvenile Atlantic salmon (Salmo salar) following emergence and dispersal from nests. A single nest was placed in each of ten replicate streams during winter, and information on the individual positions $( \pm 1 \mathrm{~m})$ and the body sizes of the resulting young-of-theyear (YOY) juveniles was obtained by sampling during the summer. In six of the ten streams, model comparisons suggested that individual body size was most closely related to the density within a mean distance of $11 \mathrm{~m}$
\end{abstract}

Communicated by Joel Trexler.

S. Einum $(\bowtie) \cdot$ G. Robertsen

Department of Biology, Centre for Conservation Biology,

Norwegian University of Science and Technology,

7491 Trondheim, Norway

e-mail: sigurd.einum@bio.ntnu.no

\section{S. Einum}

Norwegian Institute for Nature Research,

Tungasletta 2, 7485 Trondheim, Norway

K. H. Nislow

USDA Forest Service Northern Research Station,

201 Holdsworth NRC, 160 Holdsworth Way,

Amherst, MA 01003, USA

S. McKelvey

Cromarty Firth District Salmon Fisheries Board,

c/o C.K.D. Falbraith, 17 Old Edinburgh Road,

Inverness IV2 3HF, UK

\section{J. D. Armstrong}

Fisheries Research Services Freshwater Laboratory,

Faskally, Pitlochry, Perthshire PH16 5LB, UK (range 2-26 m). A link between body size and density on such a restricted spatial scale suggests that dispersal from nests confers energetic benefits that can counterbalance any survival costs. For the four remaining streams, which had a high abundance of trout and older salmon cohorts, no single spatial scale could best describe the relation between YOY density and body size. Energetic benefits of dispersal associated with reduced local density therefore appear to depend on the abundance of competing cohorts or species, which have spatial distributions that are less predictable in terms of distance from nests. Thus, given a trade-off between costs and benefits associated with dispersal, and variation in benefits among environments, we predict an evolving and/or phenotypically plastic growth rate threshold which determines when an individual decides to disperse from areas of high local density.

Keywords Drift feeding - Density dependence $\cdot$ Natal dispersal $\cdot$ Shadow competition $\cdot$ Suspension feeding

\section{Introduction}

Fitness effects of dispersal have important consequences for evolution of dispersal-related traits as well as for population dynamics (reviewed in Clobert et al. 2001). The fitness of individuals in relation to dispersal can be divided into two components: the fitness cost of dispersing a given distance (reviewed by Rankin and Burchsted 1992), and the fitness pay-off when arriving at a location with a given environmental quality. For organisms with spatial aggregations of propagules (seeds, eggs or offspring), local density may be one of the environmental conditions that influences fitness. Typically, the distribution of dispersal distances can be described by some type of exponential 
decline (i.e. leptokurtic distribution; Kot et al. 1996), such that a localized measure of density declines with distance from the source aggregation. Dispersal to a location with lower local density will then in many cases yield an energetic benefit due to reduced competition for resources (Suzuki et al. 2003; Gunton and Kunin 2009).

However, in many situations, density-dependent effects occur on some indeterminate spatial scale, so that it is difficult to assess the potential fitness consequence of dispersing any given distance from a local aggregation. A good example is provided by suspension-feeding animals living in habitat characterized by a unidirectional flow of water (such as streams and rivers) which affects the distribution and dispersal of both the suspension feeders and their prey. For these species, short-distance downstream dispersal from patches of high density can negatively affect consumption and growth rates via shadow competition (Wilson 1974; Lubin et al. 2001; Fig. 1), as upstream individuals filter prey items from the water column. It is only when individuals disperse far enough downstream to escape this 'shadow' that they would expect to reap the benefits of reduced local density (i.e. the situation when $L=1$ in Fig. 1b). The extent to which dispersal distance influences fitness pay-offs will then depend on the relationship between the spatial scale of variation in density (the shape of the curve in Fig. 1a) and the corresponding scale over which competition can occur (the value of $L$ in Fig. 1b).

For most mobile organisms, there is little knowledge about the spatial scale over which density influences fitness. This deficiency is in strong contrast to our understanding of plants, for which an extensive body of empirical studies and a strong theoretical basis of interpretation exists (e.g., Lortie et al. 2005; Gunton and Kunin 2007, 2009; Spigler and Chang 2008). Empirical studies of density-dependent processes in animals commonly deal with a more or less arbitrary and often rather coarse spatial scale (Ray and Hastings 1996). The lack of information on the spatial scale of density dependence prevents a thorough understanding of the selective pressures shaping dispersal.

Salmonid fishes are among those mobile organisms that are best suited for conducting controlled experimental approaches to study scale of density dependence in tandem with dispersal. It is possible to produce fertilized eggs of salmonids that can be planted out in different spatial configurations, and to map the distribution and performance of the resulting juveniles. Furthermore, this can be done in habitats that are known to be suitable for the species, but where it is absent due to a lack of access for naturally reproducing individuals (i.e. areas above migration barriers that adults returning from oceanic migrations cannot reach). This approach has been used
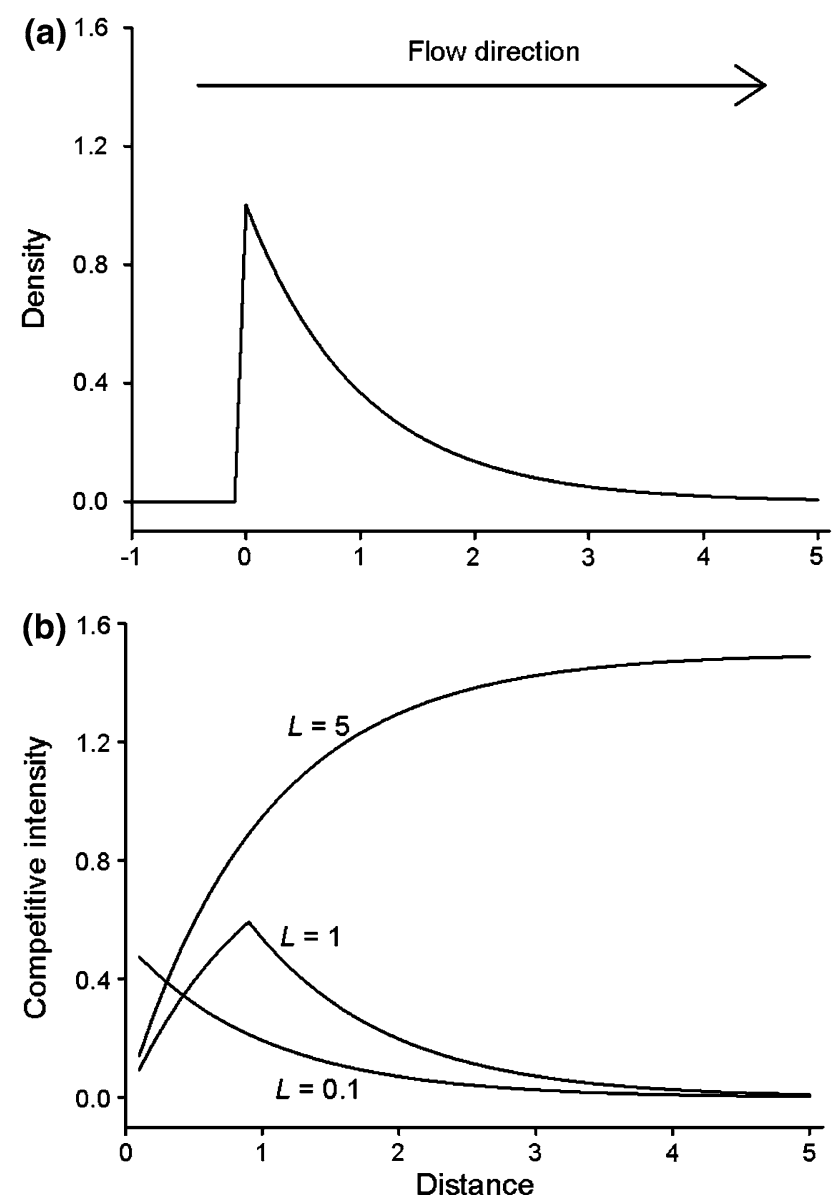

Fig. 1 a Hypothetical distribution of individuals that have dispersed uni-directionally from a single source due to a hydrodynamic force (solid line, $y=\mathrm{e}^{-x}$ ). Given such a distribution combined with transport of prey items following the hydrodynamic force (i.e. drift feeding), the level of competitive intensity for a given individual will depend on the distance within which upstream individuals influence its prey availability (i.e. shadow competition). b Here, this effect is illustrated by modeling competitive intensity experienced by individuals located at different distances as definite integrals of the distribution equation over upstream intervals of different lengths $L$ (i.e. different spatial scales of competitive interactions). According to this model, if the spatial scale of competitive interactions is sufficiently large (e.g., $L=5$ ), individuals that have dispersed furthest from the source experience the highest level of competitive intensity, whereas this is not the case for lower values of $L$. Competitive intensities for $L=0.1$ and $L=5$ have been multiplied by 5 and 2 , respectively, for improved clarity

extensively to study spatial aspects of the ecology of Atlantic salmon (Salmo salar) in recent years. The spatial distribution of eggs over small scales (100s of meters) has been shown to influence the spatial distribution of the resulting juveniles, typically creating areas of high density in the vicinities of nests and with initial dispersal occurring predominantly in a downstream direction (Beall et al. 1994; Crisp 1995; Webb et al. 2001; Einum and Nislow 2005; Einum et al. 2008; Foldvik et al. 2010). The growth of juvenile salmonids is also clearly shaped by 
intraspecific competition, as evidenced by studies using the traditional mean-field approximation of quantifying density (total number/area) in selected stream sections and observing negative correlations between these densities and mean body size among different sites and/or years (e.g., Crisp 1993; Jenkins et al. 1999; Keeley 2001; Nordwall et al. 2001; Imre et al. 2005; Lobón-Cerviá 2005; Einum et al. 2006). Juvenile salmon are primarily passive suspension feeders, defending territories in running waters (e.g., Cutts et al. 1999) and consuming invertebrates drifting downstream. They are therefore subject to shadow competition (Elliott 2002), and the issue of spatial scale of competitive interactions (Fig. 1) is clearly relevant and biased to upstream effects.

Predictions regarding the spatial scale of shadow competition in juvenile salmon (i.e. the length of "shadows" created by feeding individuals) can, at least in theory, be based on distances over which individual invertebrates remain in the drift before re-settling on the substrate. Assuming that removal of individuals from the drift at a given location has negligible effects on the downstream density of benthic individuals, the number of individuals entering the drift from the benthos at a given location will be independent of upstream predator density. The spatial scale of shadow competition will then be determined by the distance individual invertebrates move during a single drifting event. Estimates of invertebrate drift distances in streams vary considerably both among taxa and life stages, and with respect to environmental conditions such as time of day, current velocity, depth and substrate quality (reviewed by Brittain and Eikeland 1988). Yet, most estimates of mean drift distances for aquatic insect larvae, which typically dominate the juvenile salmon diet, lies within a few tens of meters, and sometimes less than a meter (Elliott 1971, 2002; Townsend and Hildrew 1976; Allan and Feifarek 1989; Lancaster et al. 1996) suggesting an approximate scale over which an upstream individual fish can be predicted to influence a downstream one.

Is it possible to obtain information on the spatial scale over which juvenile salmonids may influence each other's food availability following emergence in a field situation? Here, we aim to do so by assuming that spatial variation in Atlantic salmon body size ca. 2 months after emergence from nests is in part caused by spatial variation in competition intensity (i.e. density-dependent growth). We created spatial variation in young-of-the-year (YOY) juvenile density by planting single nests in each of ten replicate streams, and obtained detailed information $( \pm 1 \mathrm{~m})$ on the individual positions and the body sizes of the resulting juveniles. We then compared models to identify the spatial scale over which body size was best described by density.

\section{Materials and methods}

Study sites and stocking

A sample of ten female and ten male Atlantic salmon caught in a fish trap in the River Blackwater, a tributary to the River Conon, Ross-shire, Northern Scotland, during October 2007, were used to produce ten full-sibling family groups. The fertilized eggs were incubated in a hatchery at Contin where the family groups were kept separate in hatchery trays. Eyed eggs were out-planted in ten small tributaries to the River Conon, during 17-26 February 2008. All these streams are located above migration barriers and hence are without natural salmon spawning. Natural brown trout populations were present in all but one of the streams (Table 1). In addition, older salmon $(\geq 1+$ age $)$ resulting from stockings in previous years were present in seven of the streams.

Each stream received a single nest containing an equal number of eggs from all the 10 family groups. The eggs from the different family groups were placed in separate Vibert boxes (Federation of Fly Fishermen, Bozeman, MT, USA) which were placed within a depression in the gravel bed of the stream and covered with gravel and larger stones. Two stocking densities were used, one low $(1,000$ eggs per nest, with 100 from each family), and one high (3,000 eggs per nest, with 300 from each family), and these were assigned randomly to the different streams. The rationale for the two stocking treatments was to increase the potential for overall variation in environmental conditions among streams beyond that provided by other biotic and abiotic sources. This, in combination with genotyping of captured juveniles, will allow for quantification of consistency in relative family performance among environments in a subsequent paper. However, due to the relatively low number of replicate streams and the presence of other sources of environmental variation among them, these data are not suitable for testing for effects of initial population-level density on overall juvenile movement, growth or survival. These are topics that are well covered by previous salmonid studies (e.g., Gee et al. 1978; Gardiner and Shackley 1991; Crisp 1993, 1995; Jonsson et al. 1998; Jenkins et al. 1999; Keeley 2001; Nordwall et al. 2001; Imre et al. 2005; Einum and Nislow 2005; Einum et al. 2006, 2008; Finstad et al. 2009).

\section{Sampling}

During 15-24 July 2008, the streams were sampled to obtain information on the spatial distribution and body size of the resulting YOY. Each stream was electrofished in a section stretching from $150 \mathrm{~m}$ below the nest-site to $50 \mathrm{~m}$ upstream, or until a migration barrier was reached within 
Table 1 Number of YOY and older juvenile Atlantic salmon (Salmo salar) and brown trout (Salmo trutta) caught and their mean body length $\pm 1 \mathrm{SD}$ (BL, mm) during electrofishing in 10 different study sites of the Conon River

\begin{tabular}{|c|c|c|c|c|c|c|c|c|c|c|c|c|}
\hline \multirow[t]{2}{*}{ Stream } & \multirow[t]{2}{*}{$W$} & \multirow[t]{2}{*}{$M$} & \multirow[t]{2}{*}{$P$} & \multicolumn{2}{|c|}{ Salmon YOY } & \multicolumn{2}{|c|}{ Salmon > YOY } & \multicolumn{2}{|c|}{ Trout YOY } & \multicolumn{2}{|c|}{ Trout $>$ YOY } & \multirow[t]{2}{*}{$\mathrm{R}_{\mathrm{YOY}}$} \\
\hline & & & & $n$ & BL & $n$ & $\mathrm{BL}$ & $n$ & $\mathrm{BL}$ & $n$ & $\mathrm{BL}$ & \\
\hline 1. Allt Aradaidh & 2.1 & 10 & 2 & 71 & $47 \pm 4$ & - & & 131 & $44 \pm 6$ & 145 & $102 \pm 21$ & 0.14 \\
\hline 2. Distillery Burn & 2.7 & - & 1 & 50 & $52 \pm 5$ & 2 & $125 \pm 16$ & 14 & $49 \pm 5$ & 64 & $136 \pm 28$ & 0.24 \\
\hline 3. Gleann Chorainn & 3.7 & 22 & 2 & 279 & $49 \pm 3$ & 19 & $119 \pm 6$ & 3 & $54 \pm 5$ & 24 & $127 \pm 22$ & 0.74 \\
\hline 4. Tuill Bhain & 2.6 & 38 & 1 & 208 & $44 \pm 3$ & 83 & $88 \pm 14$ & 23 & $41 \pm 4$ & 18 & $99 \pm 27$ & 0.61 \\
\hline 5. Coire a Bhuic & 3.8 & 21 & 3 & 167 & $48 \pm 6$ & - & & 8 & $45 \pm 8$ & 22 & $138 \pm 19$ & 0.81 \\
\hline 6. Am-fuar Alltan & 1.1 & 16 & 2 & 207 & $37 \pm 3$ & - & & - & & - & & 1.00 \\
\hline 7. Upper Meig & 1.5 & - & 2 & 140 & $40 \pm 3$ & 1 & 83 & 20 & $39 \pm 4$ & 41 & $113 \pm 31$ & 0.76 \\
\hline 8. Chaisecain & 2.7 & - & 2 & 493 & $49 \pm 4$ & 6 & $146 \pm 4$ & 0 & & 10 & $143 \pm 27$ & 0.98 \\
\hline 9. Scardroy Burn & 4.8 & - & 1 & 616 & $49 \pm 4$ & 33 & $110 \pm 12$ & 39 & $58 \pm 4$ & 16 & $118 \pm 19$ & 0.81 \\
\hline 10. Glen Meinich & 5.4 & - & 2 & 208 & $48 \pm 4$ & 157 & $87 \pm 15$ & 1 & 48 & 10 & $133 \pm 20$ & 0.58 \\
\hline
\end{tabular}

Mean stream width $(W, \mathrm{~m})$ and number of complete passes $(P)$ of electrofishing is given. Location of upstream migration barrier $(M$, if present) is given in distance $(\mathrm{m})$ upstream from nest. $\mathrm{R}_{\text {YOY }}$ gives the ratio between "effective abundance" of YOY salmon and all salmonids (see "Materials and methods')

those $50 \mathrm{~m}$ (Table 1). From one to three complete electrofishing passes were performed depending on logistic constraints (Table 1). The location $( \pm 1 \mathrm{~m})$ along the length of the stream of each individual fish was recorded before they were killed and put in individual tubes filled with ethanol. Fish body lengths $( \pm 1 \mathrm{~mm})$ were measured within 2 weeks of sampling. We recorded the location of other fish captured (trout and older salmon) on a coarser spatial scale (10-m sections) and measured the body length of these fish in the field. These were released back into the stream after completion of sampling. We also measured the wetted width of the streams at $10-\mathrm{m}$ intervals.

\section{Modeling and statistical analyses}

To describe the overall spatial distribution of salmon YOY relative to their location of origin (i.e. nests), we first calculated the density of juveniles per meter stream (meterspecific densities) as the numbers captured divided by the width of the stream at each location. Widths of streams used in these calculations were the wetted widths at the measuring transect closest to each location (i.e. at a maximum distance of $5 \mathrm{~m}$ from the location). We then modeled these densities as a smoothed function of distance to the nest while allowing for different intercepts among streams using the gam function with a Gaussian error distribution within the mgcv package (Wood 2004) in R 2.6.0 for Windows (R Development Core Team 2008).

As a first approach to examine relations between local density and body size, meter-specific mean body sizes were calculated for each stream, and related to meter-specific densities. To examine the spatial scale of association between density and body size further, we created two-dimensional matrices that represented the pairwise distances $d_{i, j}$ between all locations yielding captures for each stream. Assuming that the effect of individuals at location $j$, $N_{j}$, on individuals at location $i$ can be modeled as a linearly decreasing function with increasing distance $d_{i, j}$, and that there is a minimum distance $d^{*}$ over which there is no effect, the relative effect $f\left(d_{i, j}\right)$ of different neighboring locations can be modeled as:

$f\left(d_{i, j}\right)= \begin{cases}\left(1-\frac{d_{i, j}}{d^{*}}\right) N_{j}, & d_{i, j} \leq d^{*} \\ 0, & d_{i, j}>d^{*}\end{cases}$

Because streams vary longitudinally in width, the effect of an upstream neighbor may depend on the width of the stream at its location. To control for such effects, we modified the relative effect $f\left(d_{i, j}\right)$ of different neighboring locations. If the effect of an upstream neighboring location $j$ on a focal location $i$ is proportional to the width of the stream at that location, $w_{j}$, the expression for $f\left(d_{i, j}\right)$ becomes:

$f\left(d_{i, j}\right)= \begin{cases}\left(1-\frac{d_{i, j}}{d^{*}}\right) \frac{N_{j}}{w_{j}} & d_{i, j} \leq d^{*} \\ 0 & d_{i, j}>d^{*}\end{cases}$

Based on eq. 2, we calculated the spatially weighted density $D_{i}$ for individuals at each location as the summed effect of neighboring locations weighted by their pairwise distance:

$D_{i}=\sum_{j=1}^{n} f\left(d_{i, j}\right)$

To reflect the characteristic of drift feeding and shadow competition, negative values of $d_{i, j}$ in the distance matrices (individuals $j$ being downstream of focal individuals $i$ ) 
were not included when calculating $D_{i}$. These calculations can also be illustrated graphically (Fig. 2).

Values of $D_{i}$ were calculated for a range of values of $d^{*}$ from 1 (only influenced by individuals caught within the same meter) to 50 (influenced by individuals less than $50 \mathrm{~m}$ upstream). For five of the streams, migration barriers prevented dispersal of juveniles upstream of the sampled area (Table 1). Thus, for these sites we had information on distribution of neighbors for all captured fish independent of the value of $d^{*}$. For the five other streams, no such barriers were present. Because we use a multi-model selection approach and the Akaike information criteria (AIC, see below) to compare models that include density within different distances, the same individuals have to be included in all analyses for a given stream across the tested range of $d^{*}$. For example, when comparing models ranging in $d^{*}$ from 0 to 50 , individuals within $50 \mathrm{~m}$ from the uppermost capture location must be excluded in all models, even if information is present for all individuals for $d^{*}=0$. For the streams lacking migration barriers, we therefore had to exclude the juveniles being captured within less than the chosen distance $d^{*}$ from the uppermost capture location. To evaluate how this might have influenced the results, we conducted two sets of analyses, with one looking at the effect of density for values of $d^{*}$ up to $50 \mathrm{~m}$, and one for values of $d^{*}$ up to $25 \mathrm{~m}$. If the observed patterns in these two sets of analyses differ much, then the results are sensitive to the exclusion of individuals in five of the streams.

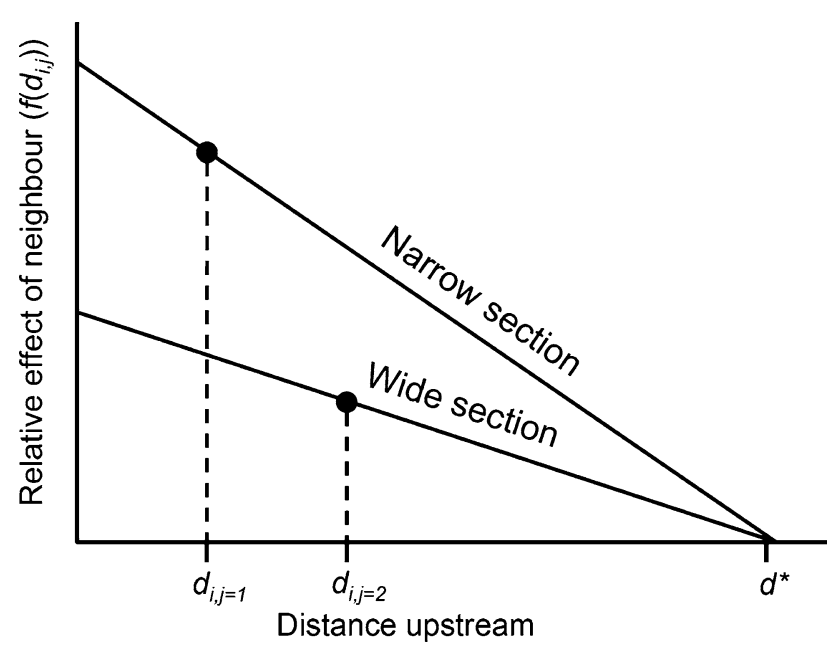

Fig. 2 Graphic illustration of the calculation of spatially weighted density according to Eqs. 1-3. In this example, the focal individual, $i$, has two other individuals $(j=1$ and 2$)$ upstream and within the distance $d^{*}$ where they can influence food availability. The slope and intercept of the lines (i.e. function $f$ ) depend on the width of the stream at the location occupied by the individual $j$. In this scenario, according to Eq. 3, the spatially weighted density for individual $i$ will be calculated as $f\left(d_{i, j=1}\right)+f\left(d_{i, j=2}\right)$
Linear models using body length as the dependent variable and spatially weighted density as the independent variable were constructed, and the performance of models for different values of $d^{*}$ were compared using AIC. The modeling of the relationship was assessed to be successful if, for a given distance $d^{*}$ smaller than the maximum value of $50 \mathrm{~m}$, there existed a local minimum AIC with a value at least $2 \mathrm{U}$ smaller than both the global maximum and all other local minima (Burnham and Anderson 2002).

Ideally, studies of density-dependent processes within a cohort of salmonids should also analyze for effects of intra-specific inter-cohort competition as well as interspecific competition. In the present study, this was prevented due to a lack of sufficient spatial resolution of the data for these other types of fish. We therefore assessed whether successful modeling of density-dependent growth of YOY salmon depended on the relative abundance of brown trout and over-yearling salmon. The allometry between food consumption rate and body size suggests that the total food consumption by a population scales proportionally with $\Sigma$ bodylength $^{2}$ (Post et al. 1999). We calculated this "effective abundance" for YOY salmon and for all fish caught for each stream. The ratio between these two values, $\mathrm{R}_{\mathrm{YOY}}$, should therefore be correlated with the proportion of the total food consumption within the stream being consumed by YOY salmon, and would therefore scale negatively with the potential competitive effect of older salmon and trout. We compared this ratio in streams where the modeling was successful to those where it was not.

For streams where the modeling was successful, $d^{*}$ was used to calculate the spatially weighted meter-specific densities. When doing this for streams without upstream migration barriers we excluded locations depending on the stream specific value of $d^{*}$ to maximise the sample size for each stream (e.g., if $d^{*}$ was identified to be $10 \mathrm{~m}$, we excluded only locations within the upper $10 \mathrm{~m}$ of the sampled stretch). We then used these to obtain the relationships between spatially weighted density and meterspecific mean body lengths.

All modeling and analyses were performed using $\mathrm{R}$ 2.6.0 for Windows (R Development Core Team 2008).

\section{Results}

A total of 2,439 YOY Atlantic salmon were captured in the ten study sites (Table 1). Although there was some variation in the spatial distribution of densities among streams (Fig. 3), the gam identified a clear overall tendency for densities to be highest in the vicinity of nests, and densities decreased more rapidly in the upstream direction from the nest compared to in the downstream direction (Fig. 4). 
Fig. 3 Local density (within each longitudinal meter of stream sampled) of juvenile Atlantic salmon (Salmo salar) relative to location of nest of origin $(0 \mathrm{~m}$, negative values upstream and positive downstream of nest) in ten different study sites $(S 1-S 10)$ in the Conon River. A total of 2,439 juveniles were sampled during 15-24 July 2008 (a)
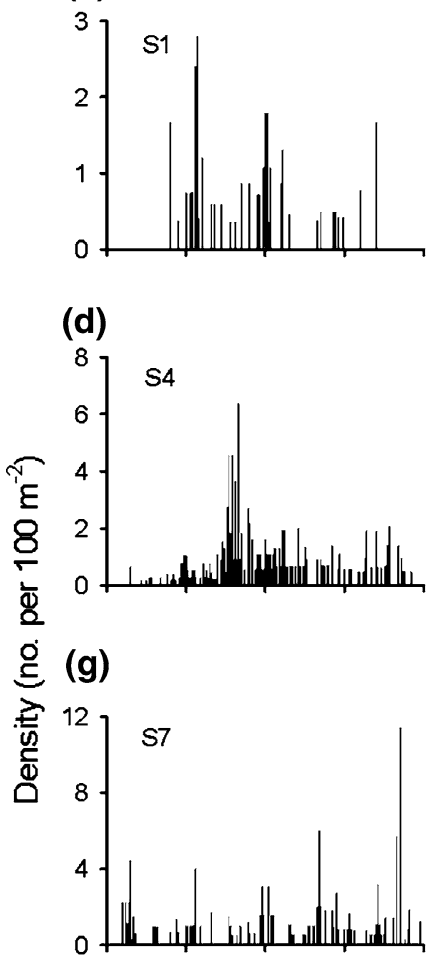

(b)

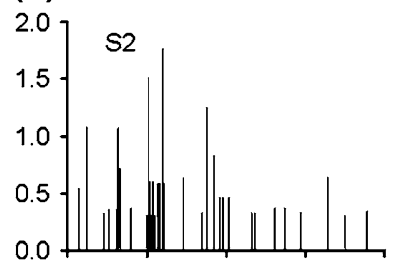

(e)

(c)

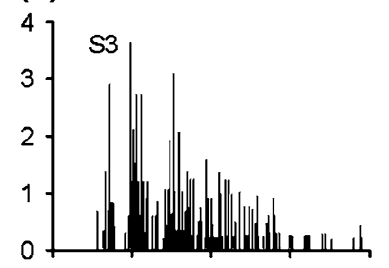

(f)

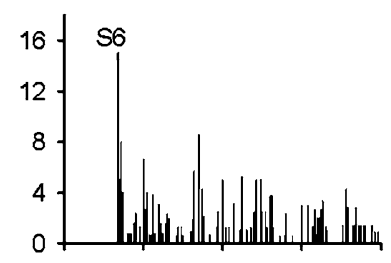

(h)

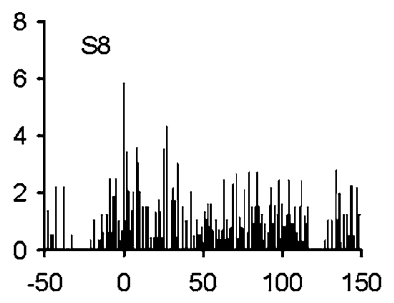

(i)

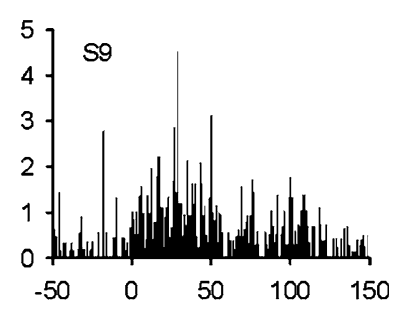

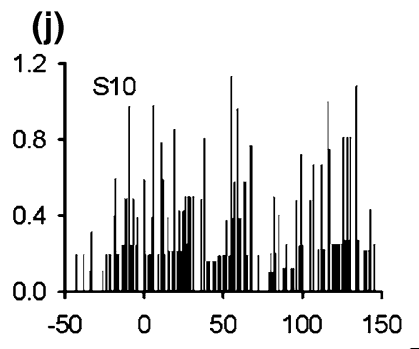

Distance from nest location (m)

Meter-specific mean body size was poorly correlated with meter-specific mean densities and was significant for only one stream (Table 2). Examination of $\triangle \mathrm{AIC}$ values for linear models suggested substantial effects of spatial scale on the quality of models relating juvenile salmon body size to spatially weighted density for many of the streams (Fig. 5). According to our criteria (see "Materials and methods"), the models successfully identified a spatial scale that best described the relation between density and body size in six of the ten streams (S3, S5, S6, S7, S8 and S9). Among these streams, the spatial scale yielding a minimum AIC value ranged from 2 to $26 \mathrm{~m}$, with an average of $11 \mathrm{~m}$. Thus, this was the spatial scale over which body length was most closely related to the density of neighbors. These results were relatively insensitive to changing the maximum potential distance of influence to $25 \mathrm{~m}$ (compare dashed and solid lines in Fig. 5).
One of the remaining four streams (S10) had a relatively strong decrease in AIC values with increasing spatial scale, reaching a minimum value at $50 \mathrm{~m}$. This may suggest a larger spatial scale of relation between density and body size in this stream. However, when reducing the maximum potential spatial scale to $25 \mathrm{~m}$ (and increasing the sample size), this pattern disappeared, making this result inconclusive. For two of the other sites (S1 and S2), $\triangle \mathrm{AIC}$ values were below or close to 2 over most of the range in spatial scale. For the remaining site (S4), two local minima that differed by less than 2 were found. Thus, for these four streams, conclusions could not be reached regarding the spatial scale of association between density and body size. The ratio between "effective abundance" of YOY salmon and total salmonids, indicating the proportion of the total food consumption within the stream being consumed by YOY salmon, was significantly lower in the streams where the modeling was not successful compared to the others 


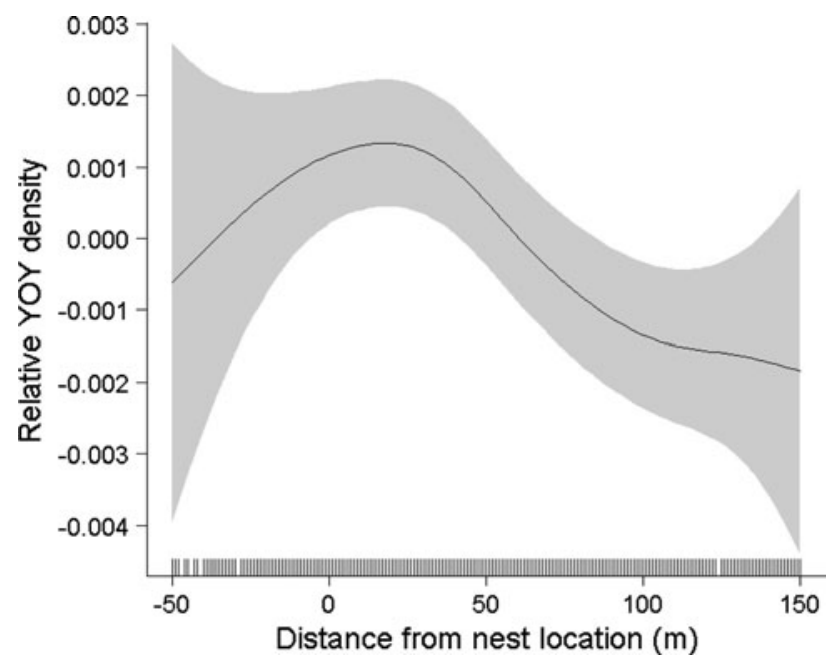

Fig. 4 Estimated smoothing curve (shaded area represents 95\% confidence interval) for the generalized additive model describing the overall spatial variation in YOY Atlantic salmon abundance in 10 study sites in the River Conon as a function of distance from nest site. Zero represents the location of the nest, and negative location values are in the upstream direction. Etchings on the inside of the $x$-axis indicate locations of data points. Effective degrees of freedom for the smoother are 3.03, and the significance is $P=0.015$

Table 2 Correlations between meter-specific mean body size and meter-specific mean densities of YOY Atlantic salmon in 10 different study sites of the Conon River

\begin{tabular}{lrrl}
\hline Stream & \multicolumn{1}{l}{$r$} & $d f$ & $P$ \\
\hline 1 & 0.01 & 32 & 0.950 \\
2 & 0.01 & 31 & 0.962 \\
3 & -0.19 & 95 & 0.062 \\
4 & 0.05 & 104 & 0.622 \\
5 & -0.19 & 78 & 0.098 \\
6 & 0.08 & 79 & 0.455 \\
7 & -0.16 & 76 & 0.172 \\
8 & -0.13 & 134 & 0.147 \\
9 & -0.23 & 156 & 0.003 \\
10 & -0.02 & 108 & 0.819 \\
\hline
\end{tabular}

(Table 1; Wilcoxon rank-sum test $P=0.014$ ). Thus, the potential effect of inter-cohort and intra-specific competition was higher in these streams.

Five of the six streams where the models were successful showed significant negative relationships between spatially weighted density (calculated using Eq. 3 and stream specific values for $d^{*}$ ) and body length (Fig. 6). On average, $17 \%$ (range $6-27 \%$ ) of the spatial variation in mean body size could be explained by variation in density in these streams. The remaining stream (S6) was the one stream among these six that had the smallest YOY salmon (Table 1).

\section{Discussion}

By planting out eggs and collecting high resolution data on the resulting spatial distribution of YOY juveniles and their body sizes in ten replicated streams, we were able to obtain information on the spatial scale of dispersal and densitydependent growth. Limited dispersal caused densities of YOY to be highest in the vicinity of nests. Using model comparisons, we successfully identified a spatial scale that best described the relation between density and body size in six of the ten streams. In these sites, body size was most closely related to the density within a distance of on average $11 \mathrm{~m}$ upstream of focal fish. Because variation in body size is an integrated measure of performance over an extended period of time from onset of feeding, this result suggests a high level of temporal stability in the small-scale spatial distribution of individuals once the initial period of dispersal from nests is completed. The link between body size and density on such a restricted spatial scale, combined with the observed decrease in number of individuals with increasing distances from nests over larger spatial scales, suggests selection for increased dispersal (i.e. a situation similar to the curve for $L=0.1$ in Fig. 1b). However, benefits of dispersing may depend on the abundance of competing cohorts or species, which have a spatial distribution that will be less predictable in terms of distance from nests. This is indicated by the observation that for the four remaining streams, which had a significantly higher abundance of trout and older salmon cohorts, no single spatial scale could best describe the relation between YOY density and body size.

In five of the six streams where model comparisons were successful in identifying a spatial scale that best described relations between density and body size, there was a significant negative relation between spatially weighted density and body size, consistent with density-dependent growth. However, in one of the streams where AIC analyses suggested an effect of density over small spatial scales (S6), no significant negative relationship between density and body size was observed. In fact, if anything, there was a positive trend between density and body length. In this stream, only YOY salmon were present, so this result was not due to presence of other fish. An initial positive relationship between density and body size may arise if early and/or larger emerging juveniles are competitively dominant and remain close to the nest site where density is higher, whereas smaller and later emerging ones are displaced to less dense areas. This is consistent with previous observations on size differences between drifting and resident salmon during and shortly following the period of emergence (Johnston 1997; Bujold et al. 2004; Einum and Fleming 2004). Under this scenario, an initial positive relationship between local density and body size will be 
Fig. 5 Delta AIC values for linear models relating individual juvenile salmon body size to spatially weighted density of upstream neighbors within different distances up to $50 \mathrm{~m}$ upstream of focal individuals in ten streams $(\mathbf{a}-\mathbf{j}$, solid lines $)$.

For five of the streams (a, c-f), upstream migration barriers allowed inclusion of all individuals within the sampled stretch. For remaining streams, fish in the upper $50 \mathrm{~m}$ of the sampled stretch were excluded due to missing information on upstream neighbors. For these streams, additional analyses were performed testing for effects of density over distances up to $25 \mathrm{~m}$ (dashed lines) to allow for inclusion of larger samples. Values of $d^{*}$ (i.e. minimum distance over which there is no effect of neighbors) minimizing AIC values are given (with values for $25 \mathrm{~m}$ analyses in parantheses), as well as associated $r^{2}$ values for the streams where the modeling approach was successful (a)

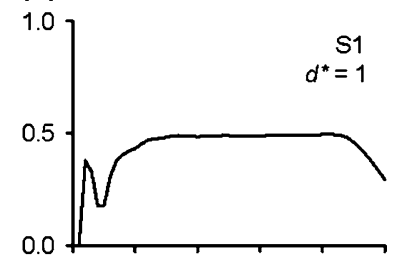

(d)

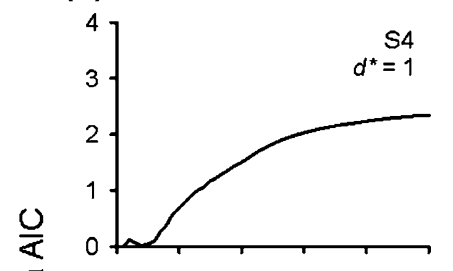

(g)

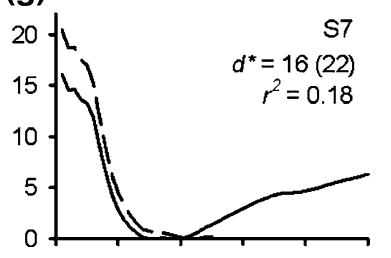

(b)

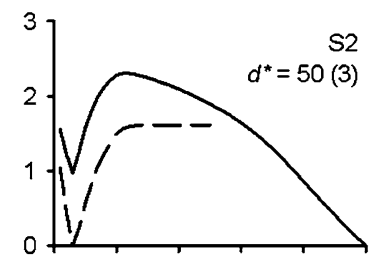

(e)

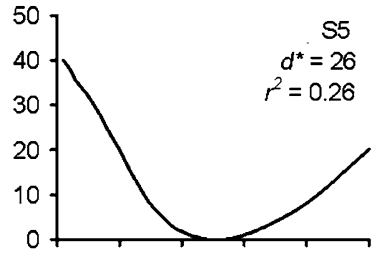

(h)

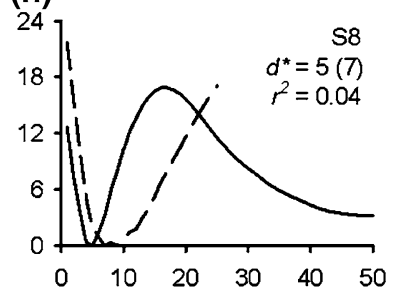

(c)

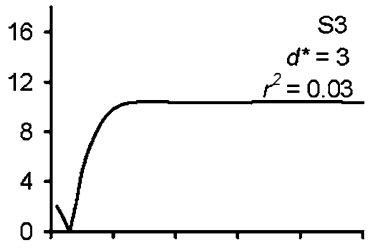

(f)

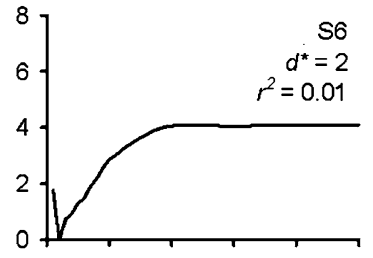

(i)

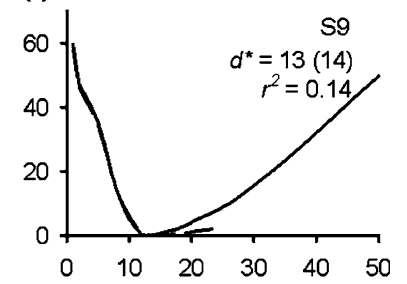

(j)

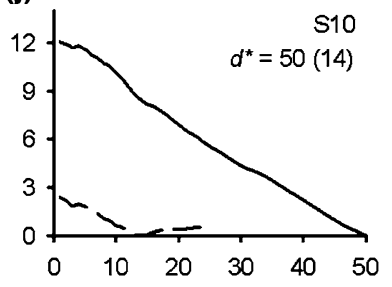

Distance used for density calculation (m)

Fig. 6 Relationships between spatially weighted density (Eq. 3) and meter-specific mean body length of juvenile salmon in six different streams. Streamspecific values of $d^{*}$ used to calculate spatially weighted densities were those identified as giving the lowest AIC value (Fig. 5). Linear regression results are given; regression lines are included for significant models. For comparisons with conventional measurements of density, a homogenous density of one fish $\mathrm{m}^{-2}$ corresponds to a spatially weighted density of 17 given the mean value of $d^{*}$ found in this study $(11 \mathrm{~m})$ and the mean width of the streams (3 m) (a)

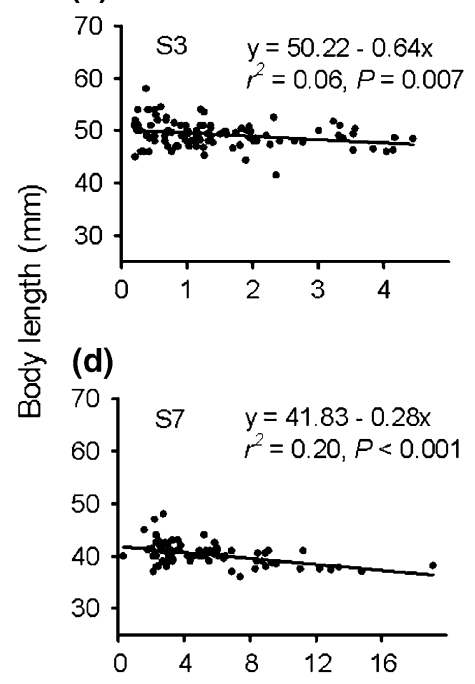

(b)

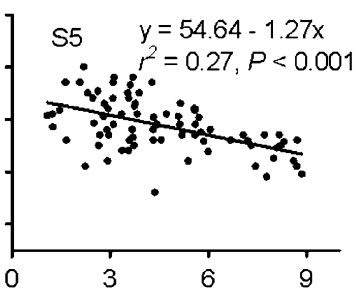

(e)

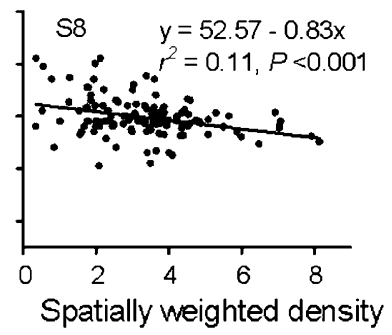

(c)

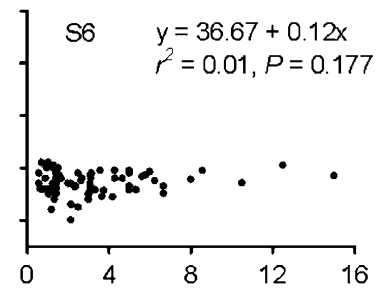

(f)

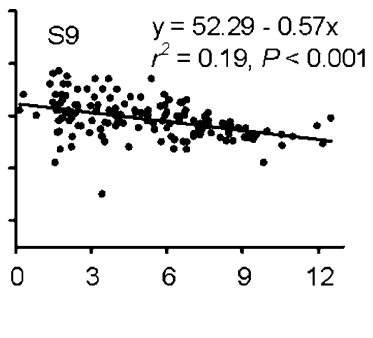


reversed after a sufficient amount of time with densitydependent growth. The potential for detecting such initial positive relationships between density and body size (or not detecting effects of density-dependent growth) will have been largest in S6 due to their small body size (Table 1).

Given the small spatial scale over which variation in growth can be linked to density, and the decrease in density over this scale when moving from nests (see also Beall et al. 1994; Crisp 1995; Webb et al. 2001; Einum et al. 2008; Foldvik et al. 2010), why do emerging juvenile salmon not disperse more? One potential explanation would be that the spatial distribution of spawning in natural rivers is such that the probability function for experienced local levels of competition is independent of dispersal distance (i.e. a more flat or unpredictable curve in Fig. 1a). This would be the case if nests are well distributed throughout the stream with short distances separating them, such that dispersers from one nest has a high probability to encounter individuals from nests in nearby locations. Restricted physical habitat requirements for spawning (Armstrong et al. 2003) in combination with present-day low abundances of Atlantic salmon may cause this scenario to seem unlikely for many streams. Furthermore, maps showing spatial distributions of salmonid nests indicate substantial patchiness (Geist and Dauble 1998; Moir et al. 2004; Isaak and Thurow 2006). However, if the distribution of spawning was more homogenous under higher historical abundances, this may have shaped the evolution of this trait. Furthermore, as indicated by our observations, benefits of dispersing may depend on the abundance of competing cohorts or species.

An alternative but not mutually exclusive explanation for restricted dispersal deals with costs of dispersal which have to be traded off against the benefit of experiencing reduced local density. Early juvenile stages appear to be vulnerable to starvation (Kennedy et al. 2008), and the risk of negative energy balance may increase if dispersal entails energy costs and relatively sparse feeding opportunities. Furthermore, early stages are highly vulnerable to predation from older salmonid fishes (Henderson and Letcher 2003). These predators are mainly drift feeders, and thus dispersal appears likely to increase the risk of encountering one of them. The idea that dispersal represents a cost to be traded off against the growth benefit is also consistent with the observation that high local density during emergence has weak or no effects on distance moved for successful dispersers (i.e. those surviving) but causes reduced survival (Einum and Nislow 2005).

Under this framework, where dispersal entails a tradeoff between costs and benefits, individuals experiencing low growth rates would be expected to disperse from nests to increase their fitness. Thus, one might imagine the evolution of a growth rate threshold that dictates whether an individual should stay or disperse. Similar thresholds have previously been implied to control movement of animals, including growth rate thresholds controlling migrations from streams to lakes in brown trout (Forseth et al. 1999), and body size thresholds controlling migrations from streams to the ocean in anadromous brown trout and Atlantic salmon (Økland et al. 1993) as well as natal dispersal in mammals (Nunes and Holekamp 1996). However, because unfavorable growth conditions may be a condition periodically experienced throughout the population, such a rule should perhaps not be based on absolute growth rates. Rather, the decision to disperse should be based on individual growth rate relative to that of other individuals in the vicinity. Such a relative growth rate threshold has been inferred in an experimental study of Atlantic salmon, where individuals experiencing the lowest growth within stream channels dispersed, but where variation in dispersal rates among stream channels was unrelated to mean growth conditions (Einum and Fleming 2004).

Although the determination of spatial scales for densitydependent growth conducted in the present study is novel, the existence of such density dependence for juvenile salmonids has been well known. As we have shown here, the inferred strength of density dependence may depend on the spatial scale over which density and growth or body size is measured. This will be particularly true if densities vary much over relatively small spatial scales (10s of meters). Previous published studies successfully detecting densitydependent growth of salmonids in the wild (e.g., Crisp 1993; Jenkins et al. 1999; Keeley 2001; Nordwall et al. 2001; Imre et al. 2005; Lobón-Cerviá 2005; Einum et al. 2006) have sampled sections of streams ranging widely in area (ca. $40-2,500 \mathrm{~m}^{2}$, section lengths are less commonly reported, but likely vary from ca. 10-500 m). Based on the present results, if one would like to accurately model the strength of density-dependent growth, we would perhaps recommend section lengths for such studies to be at least $10 \mathrm{~m}$, and not exceeding $20 \mathrm{~m}$. However, because such designs will be prone to edge effects (e.g., no knowledge can be obtained on the level of shadow competition experienced by individuals sampled in the upstream part of the section), it may be beneficial to measure growth or body size on only a subset of individuals caught within the lower part of each section. Furthermore, the sensitivity of such models to using different spatial scales will depend strongly on the degree of spatial autocorrelations in density in the given population, making it difficult to give general recommendations that are likely to be valid for all circumstances.

In the present study, we have demonstrated that variation in body size can be linked to density on a restricted 
spatial scale relative to the larger spatial scale over which dispersal from nests creates variation in density. This suggests that dispersing individuals obtain a fitness benefit in terms of increased growth rates. Given that environmental conditions have the potential to shape this benefit as well as associated costs of dispersal (discussed above), evolution of adaptive phenotypic plasticity in a threshold growth value dictating dispersal behavior is predicted (reviewed by Murren et al. 2001). For example, if cues for predator presence can be detected, juveniles may tolerate larger reductions in growth rate due to high local density before dispersing. Furthermore, given the observed heritability of dispersal traits across taxa (reviewed by Roff and Fairbairn 2001), local adaptations in the growth rate threshold may also be expected (Garcia de Leaniz et al. 2007). Further studies are required to test whether growth rate thresholds for dispersal are shaped by environmental conditions, and/or whether such thresholds are genetically variable within and among populations.

Acknowledgments We thank J. Henry, A. Foldvik, R. Kaspersson and R. Knudsen for assistance in the field, and J. Trexler and two anonymous reviewers for helpful comments. Financial support was provided by the Research Council of Norway. This study was conducted in accordance with national animal care guidelines.

Open Access This article is distributed under the terms of the Creative Commons Attribution Noncommercial License which permits any noncommercial use, distribution, and reproduction in any medium, provided the original author(s) and source are credited.

\section{References}

Allan JD, Feifarek BP (1989) Distances traveled by drifting mayfly nymphs-factors influencing return to the substrate. J North Am Benthol Soc 8:322-330

Armstrong JD, Kemp PS, Kennedy GJA, Ladle M, Milner NJ (2003) Habitat requirements of Atlantic salmon and brown trout in rivers and streams. Fish Res 62:143-170

Beall E, Dumas J, Claireaux D, Barriére L, Marty C (1994) Dispersal patterns and survival of Atlantic salmon (Salmo salar L.) juveniles in a nursery stream. ICES J Mar Sci 51:1-9

Brittain JE, Eikeland TJ (1988) Invertebrate drift—a review. Hydrobiologia 166:77-93

Bujold V, Cunjak RA, Dietrich JP, Courtemanche DA (2004) Drifters versus residents: assessing size and age differences in Atlantic salmon (Salmo salar) fry. Can J Fish Aquat Sci 61:273-282

Burnham KP, Anderson DR (2002) Model selection and multimodel inference: a practical information-theoretic approach. Springer, New York

Clobert J, Wolff JO, Nichols JD, Danchin E, Dhondt AA (2001) Dispersal. Oxford University Press, Oxford

Crisp DT (1993) Population densities of juvenile trout (Salmo trutta) in 5 upland streams and their effects upon growth, survival and dispersal. J Appl Ecol 30:759-771

Crisp DT (1995) Dispersal and growth rate of 0-group salmon (Salmo salar L.) from point-stocking to together with some information from scatter-stocking. Ecol Freshw Fish 4:1-8
Cutts CJ, Metcalfe NB, Taylor AC (1999) Competitive asymmetries in territorial juvenile Atlantic salmon, Salmo salar. Oikos 86: 479-486

Einum S, Fleming IA (2004) Does within-population variation in egg size reduce intraspecific competition in Atlantic salmon, Salmo salar? Funct Ecol 18:110-115

Einum S, Nislow KH (2005) Local-scale density-dependent survival of mobile organisms in continuous habitats: an experimental test using Atlantic salmon. Oecologia 143:203-210

Einum S, Sundt-Hansen L, Nislow KH (2006) The partitioning of density-dependent dispersal, growth and survival throughout ontogeny in a highly fecund organism. Oikos 113:489-496

Einum S, Nislow KH, McKelvey S, Armstrong JD (2008) Nest distribution shaping within-stream variation in Atlantic salmon juvenile abundance and competition over small spatial scales. J Anim Ecol 77:167-172

Elliott JM (1971) Distances travelled by drifting invertebrates in a Lake District Stream. Oecologia 6:350-379

Elliott JM (2002) Shadow competition in wild juvenile sea-trout. J Fish Biol 61:1268-1281

Finstad AG, Einum S, Ugedal O, Forseth T (2009) Spatial distribution of limited resources and local density regulation in juvenile Atlantic salmon. J Anim Ecol 78:226-235

Foldvik A, Finstad AG, Einum S (2010) Relating juvenile spatial distribution to breeding patterns in anadromous salmonid populations. J Anim Ecol 79:501-509

Forseth T, Næsje TF, Jonsson B, Hårsaker K (1999) Juvenile migration in brown trout: a consequence of energetic state. J Anim Ecol 68:783-793

Garcia de Leaniz C, Fleming IA, Einum S, Verspoor E, Jordan WC, Consuegra S, Aubin-Horth N, Lajus D, Letcher BH, Youngson AF, Webb J, Vøllestad LA, Villanueva B, Ferguson A, Quinn TP (2007) A critical review of adaptive genetic variation in Atlantic salmon: implications for conservation. Biol Rev 82:173-211

Gardiner R, Shackley P (1991) Stock and recruitment and inversely density-dependent growth of salmon, Salmo salar L., in a Scottish stream. J Fish Biol 38:691-696

Gee AS, Milner NJ, Hemsworth RJ (1978) The effect of density on mortality in juvenile Atlantic salmon (Salmo salar). J Anim Ecol 47:497-505

Geist DR, Dauble DD (1998) Redd site selection and spawning habitat use by fall chinook salmon: the importance of geomorphic features in large rivers. Environ Manage 22:655-669

Gunton RM, Kunin WE (2007) Density effects at multiple scales in an experimental plant population. J Ecol 95:435-445

Gunton RM, Kunin WE (2009) Density-dependence at multiple scales in experimental and natural plant populations. J Ecol 97: $567-580$

Henderson JN, Letcher BH (2003) Predation on stocked Atlantic salmon (Salmo salar) fry. Can J Fish Aquat Sci 60:32-42

Imre I, Grant JWA, Cunjak RA (2005) Density-dependent growth of young-of-the-year Atlantic salmon Salmo salar in Catamaran Brook, New Brunswick. J Anim Ecol 74:508-516

Isaak DJ, Thurow RF (2006) Network-scale spatial and temporal variation in Chinook salmon (Oncorhynchus tsawytscha) redd distributions: patterns inferred from spatially continuous replicate surveys. Can J Fish Aquat Sci 63:285-296

Jenkins TM, Diehl S, Kratz KW, Cooper SD (1999) Effects of population density on individual growth of brown trout in streams. Ecology 80:941-956

Johnston TA (1997) Downstream movements of young-of-the-year fishes in Catamaran Brook and the Little Southwest Miramichi River, New Brunswick. J Fish Biol 51:1047-1062

Jonsson N, Jonsson B, Hansen LP (1998) The relative role of densitydependent and density-independent survival in the life cycle of Atlantic salmon Salmo salar. J Anim Ecol 67:751-762 
Keeley ER (2001) Demographic responses to food and space competition by juvenile steelhead trout. Ecology 82:1247-1259

Kennedy BP, Nislow KH, Folt CL (2008) Habitat-mediated foraging limitations drive survival bottlenecks for juvenile salmon. Ecology 89:2529-2541

Kot M, Lewis MA, van den Driessche P (1996) Dispersal data and the spread of invading organisms. Ecology 77:2027-2042

Lancaster J, Hildrew AG, Gjerlov C (1996) Invertebrate drift and longitudinal transport processes in streams. Can J Fish Aquat Sci 53:572-582

Lobón-Cerviá J (2005) Spatial and temporal variation in the influence of density dependence on growth of stream-living brown trout (Salmo trutta). Can J Fish Aquat Sci 62:1231-1242

Lortie CJ, Ellis E, Novoplansky A, Turkington R (2005) Implications of spatial pattern and local density on community-level interactions. Oikos 109:495-502

Lubin Y, Henschel JR, Baker MB (2001) Costs of aggregation: shadow competition in a sit-and-wait predator. Oikos 95:59-68

Moir HJ, Gibbins CN, Soulsby C, Webb J (2004) Linking channel geomorphic characteristics to spatial patterns of spawning activity and discharge use by Atlantic salmon (Salmo salar L.). Geomorphology 60:21-35

Murren CJ, Julliard R, Schlichting CD, Clobert J (2001) Dispersal, individual phenotype, and phenotypic plasticity. In: Clobert $\mathrm{J}$, Danchin E, Dhondt AA, Nichols JD (eds) Dispersal. Oxford University Press, Oxford, pp 261-272

Nordwall F, Naslund I, Degerman E (2001) Intercohort competition effects on survival, movement, and growth of brown trout (Salmo trutta) in Swedish streams. Can J Fish Aquat Sci 58:2298-2308

Nunes S, Holekamp KE (1996) Mass and fat influence the timing of natal dispersal in breeding Belding's ground squirrels. J Mammal 77:807-817

Økland F, Jonsson B, Jensen AJ, Hansen LP (1993) Is there a threshold size regulating seaward migration of brown trout and Atlantic salmon? J Fish Biol 42:541-550
Post JR, Parkinson EA, Johnston NT (1999) Density-dependent processes in structured fish populations: interaction strengths in whole-lake experiments. Ecol Monogr 69:155-175

R Development Core Team (2008) R: a language and environment for statistical computing. R Foundation for Statistical Computing, Vienna. ISBN 3-900051-07-0, http://www.R-project.org

Rankin MA, Burchsted JCA (1992) The cost of migration in insects. Annu Rev Entomol 37:533-559

Ray C, Hastings A (1996) Density dependence: Are we searching at the wrong spatial scale? J Anim Ecol 65:556-566

Roff DA, Fairbairn DJ (2001) The genetic basis of dispersal and migration, and its consequences for the evolution of correlated traits. In: Clobert J, Danchin E, Dhondt AA, Nichols JD (eds) Dispersal. Oxford University Press, Oxford, pp 191-202

Spigler RB, Chang SM (2008) Effects of plant abundance on reproductive success in the biennial Sabatia angularis (Gentianaceae): spatial scale matters. J Ecol 96:323-333

Suzuki RO, Kudoh H, Kachi N (2003) Spatial and temporal variations in mortality of the biennial plant, Lysimachia rubida: effects of intraspecific competition and environmental heterogeneity. J Ecol 91:114-125

Townsend CR, Hildrew AG (1976) Field experiments on drifting, colonization and continuous redistribution of stream benthos. J Anim Ecol 45:759-772

Webb JH, Fryer RJ, Taggart JB, Thompson CE, Youngson AF (2001) Dispersion of Atlantic salmon (Salmo salar) fry from competing families as revealed by DNA profiling. Can J Fish Aquat Sci 58:2386-2395

Wilson DS (1974) Prey capture and competition in the ant lion. Biotropica 6:187-193

Wood SN (2004) Stable and efficient multiple smoothing parameter estimation for generalized additive models. J Am Stat Assoc 99:673-686 